\title{
Effect of pattern of water supply on Vicia faba $L$. 3. Plant water relations, expansive growth and stomatal reactions
}

\author{
C. GRASHOFF \& D. R. VERKERKE \\ Centre for Agrobiological Research (CABO-DLO), P.O. Box 14, NL 6700 AA Wagenin- \\ gen, Netherlands
}

Received 28 January 1991; accepted 22 August 1991

\begin{abstract}
Leaf water potential $(\psi)$, osmotic potential $(\pi)$, turgor $(P)$ and relative water content $(R W C)$ of six faba bean cultivars were studied in a treatment with limited water availability from onset of flowering to the end of the growing season (d-d), and in a treatment with full irrigation during the same period (i-i), in the field in 1982 and 1984. $\psi, \pi$ and $P$ were linearly related to leaf $R W C$, and there were no significant cultivar effects. The osmotic potential $\pi$ at full turgor hardly differed between the water supply treatments $(-0.7 \mathrm{MPa}$ in $\mathrm{d}-\mathrm{d}$ and $-0.6 \mathrm{MPa}$ in $\mathrm{i}-\mathrm{i})$ and the slopes of $\pi$ versus $R W C$ showed no significant difference $(P<0.01)$. This indicates the absence of osmotic adjustment. Significant effects of water supply treatment on the slope of $P$ versus $R W C$ (the bulk modulus of elasticity, $B M E$ ) were absent. It is concluded that the six faba bean cultivars showed a general lack of mechanisms to keep $P$ on a high level at increasing water shortage. Internode expansive growth rate during flowering was in i-i 2 to 3 times higher than in d-d. Under controlled conditions $\left(22\right.$ or $28^{\circ} \mathrm{C} ; 400 \mu \mathrm{E} \mathrm{m}^{-2} \mathrm{~s}^{-1}$ ), expansive growth linearly declined with decreasing $P$. Maximum stomatal conductance in the field decreased with $\psi$ from an estimated maximum level of $1.0 \mathrm{~s} \mathrm{~cm}^{-1}$ (at full turgidity and light intensity $>800 \mu \mathrm{E} \mathrm{m}^{-2} \mathrm{~s}^{-1}$ ), following a negative exponential curve. It is concluded that vegetative (expansive) growth decreases faster with decreasing $P$ or $\psi$ than the stomatal conductance (and most probably faster than the rate of photosynthesis). This result, combined with the inability to maintain $P$ at increasing water shortage, helps to explain the positive effect of mild water shortage on reproductive growth of faba beans.
\end{abstract}

Keywords: faba beans, Vicia faba L., plant water relations, expansive growth, dry matter partitioning, stomatal conductance

\section{Introduction}

Growth of faba beans is very sensitive to level and pattern of water supply (Grashoff, 1990a). Turgor $(P)$ is considered as an important driving force for expansive growth, although recent research underlines that more factors are involved (van Volkenburgh \& Boyer, 1985; Nonami \& Boyer, 1989). Mechanisms to maintain turgor at declining water supply have been discovered for several species. Such mechanisms are osmotic adjustment and adaptation of bulk modulus of elasticity 
$(B M E)$. These mechanisms enable the plants to maintain a high level of expansive growth and a high rate of photosynthesis under water shortage and thus increase drought tolerance (Weatherley, 1970; Hellkvist et al., 1974; Jones \& Turner, 1978; Sobrado \& Turner, 1983).

In faba beans however, even a mild water shortage during flowering reduces the vegetative expansive growth (Grashoff, 1990a). In general, such a reduction of expansive growth is accompanied by a decrease of metabolic cell growth processes (Hsiao \& Acevedo, 1974). Consequently the sink strength of the vegetative plant top will be reduced. If the plant is not able to restore expansive growth to the original level, but concomitantly maintains assimilation rate, increasing amounts of assimilates cannot be incorporated into vegetative top tissue. The assimilate surplus may flow down to organs at a lower plant position such as the developing pods or the roots. Actually, Grashoff (1990a, 1990b) established that mild water shortage during flowering reduces stem extension and leaf expansion, and stimulates retention and growth of the first developing pods. This stimulation of reproductive growth during water shortage may be related to the absence of osmotic adjustment or $B M E$ adaptation in the vegetative top of faba beans. In the present study, this hypothesis is tested.

\section{Materials and methods}

\section{Field experiments}

Plants were grown in the field on the experimental farm Droevendaal on a humic sandy soil under five different water supply conditions. Details about materials and methods were presented in an earlier publication (Grashoff, 1990a). This study concerns plants of the two extreme treatments ' $d$-d' (limited water availability from onset of flowering to the end of the growing season), and 'i-i' (irrigated to keep the soil close to field capacity, from onset of flowering onwards).

\section{Procedure of measurements in the field}

On 7 days in 1982 and 3 in 1984, 10 to 15 neighbouring plants per treatment and per cultivar were selected (Table 1). The third fully unfolded but still expanding leaf from the top of 2 to 3 plants of each treatment and of each cultivar were sampled at $10.00 \mathrm{~h} \mathrm{a} . \mathrm{m}$. (1982) or at dawn (1984) and, with 2 to $3 \mathrm{~h}$ intervals, till $17.00 \mathrm{~h}$ (1982) or till the end of the light period (1984). $\psi$ was measured within 2 minutes after excision of each leaf. Subsequently, this leaf was frozen in liquid nitrogen and stored in small polythene cups at $-20^{\circ} \mathrm{C}$ for determination of $\pi$ and calculation of $P$. Immediately thereafter, the leaf growing one node lower than the previous one, was excised for measurement of $R W C$, using a gravimetrical procedure.

At some data, additional measurements were carried out (Table 1). In 1982, after each pair of top leaves, also the oldest leaf which was still completely green was used (for $\psi$ and $\pi$ measurements) and the leaf growing one node higher than the oldest green leaf (for $R W C$ measurements). Expansive growth in the field was mea- 
WATER SUPPLY ON VICIA FABA L. 3.

Table 1. Years, treatments, cultivars used, measurements and calendar data (presented as day/month) of the water supply experiments with faba beans.

\begin{tabular}{|c|c|c|c|c|}
\hline Year & Treatments & Varieties & Measurements & Calendar data \\
\hline \multicolumn{5}{|c|}{ Field experiments } \\
\hline 1982 & $d-d, i-i$ & $\begin{array}{l}\text { Minica, Wierboon, } \\
\text { Kristall, Felix }\end{array}$ & $\begin{array}{l}\text { 1) } \psi, \pi, P \text { and } R W C \text { of } \\
\text { upper and lower leaves } \\
\text { 2) Field measurements of } \\
\text { expansive growth. }\end{array}$ & $\begin{array}{l}\text { 1) } 9 / 6,15 / 6,17 / 6, \\
24 / 6,1 / 7,7 / 7,8 / 7 \\
\text { 2) } 17 / 6-22 / 6,22 / 6- \\
29 / 6,29 / 6-5 / 7 \\
5 / 7-9 / 7\end{array}$ \\
\hline 1984 & $\mathrm{~d}-\mathrm{d}, \mathrm{i}-\mathrm{i}$ & $\begin{array}{l}\text { Minica, Optica, } \\
\text { Alfred, Kristall }\end{array}$ & $\begin{array}{l}\text { 1) } \psi, \pi, P, \text { stomatal } \\
\text { conductance } \\
\text { 2) } \psi \text { (only), stomatal } \\
\text { conductance }\end{array}$ & $\begin{array}{l}\text { 1) } 20 / 6,11 / 7,25 / 7 \\
\text { 2) } 7 / 6,13 / 6,27 / 6,4 / 7 \text {, } \\
18 / 7,1 / 8\end{array}$ \\
\hline \multicolumn{5}{|c|}{ Controlled environment experiments } \\
\hline 1983 & $\begin{array}{l}\text { dark-light-dark } \\
\text { light-dark-light } \\
\text { dark-light-dark }\end{array}$ & $\begin{array}{l}\text { Minica } \\
\text { Minica } \\
\text { Minica }\end{array}$ & $\begin{array}{l}\psi, \pi, P, \text { expansive } \\
\text { growth } \\
\psi, \pi, P \text {, expansive } \\
\text { growth } \\
\psi, \pi P, \text { expansive } \\
\text { growth }\end{array}$ & $\begin{array}{r}11 / 5 \\
13 / 5 \\
8 / 6\end{array}$ \\
\hline
\end{tabular}

sured during and shortly after flowering.

In 1984, at five other days during June and July and one in August, only $\psi$ of the top leaves was measured, without measurements of $\pi$ and calculations of $P$, but following the same measuring scheme during a day as presented above. On all the measuring days and within half an hour after finishing the $\psi$ measurements of each series, the stomatal conductance of the youngest fully expanded leaves was measured of 3 plants, neighbouring those used for the $\psi$ measurements. Together with this measurement, radiation was measured. On all measuring days, water content of the top soil layer ( 0 to $40 \mathrm{~cm}$ ) was measured gravimetrically, close to the selected plants for the $\psi$ measurements.

\section{Experiments under controlled conditions}

Plants of cv. Minica were grown in the greenhouse in 1-1 pots, filled with peaty soil. The pots were watered daily with Hoagland solution. As soon as the 8th leaf started unfolding, the plants were placed in a room with a constant temperature of $22^{\circ} \mathrm{C}$. In two experiments (Table 1) $\psi$ and $\pi$ of the fifth leaf were measured and $P$ was calculated, prior to the start of the light period, in the middle of the light period, and prior to the end of the light period ('dark-light-dark' experiment, D-L-D) or viceversa in the L-D-L experiment. The light period in D-L-D was $5 \mathrm{~h}$ (with $10 \mathrm{~h}$ of darkness before and $9 \mathrm{~h}$ after the light period). The dark period in the L-D-L experiment was also $5 \mathrm{~h}$ (with $5 \mathrm{~h}$ of light before this dark period and $2 \mathrm{~h}$ of light afterwards, and $12 \mathrm{~h}$ of darkness to complete a 24-hours' day). Expansive growth was 
measured continuously, with an auxanometer clamped to the 7th leaf of undisturbed plants, neighbouring those used for measurements of water relations.

In the third experiment (D-L-D), plants were placed on aerated water culture (Hoagland solution) in a room at $28^{\circ} \mathrm{C}$. Water relations and expansive growth were measured in the same way as in the pot experiments.

Light intensity in these experiments was $400 \mu \mathrm{E} \mathrm{m}^{-2} \mathrm{~s}^{-1}$ (Philips HPI-lamps) and relative air humidity (measured with the porometer) varied between 30 and $50 \%$.

\section{Methods of measurement of $\psi, \pi$, stomatal conductance and expansive growth}

Leaf water potential $(\psi)$ was measured with a pressure chamber (Scholander et al., 1965). Before excision, the leaves were wrapped in small polythene bags. The chamber was pressurized at a rate of about $50 \mathrm{kPa} \mathrm{s}^{-1}$. The applied pressure at which sap was expelled from the xylem vessels was taken as a measure of $\psi$, without correcting for the osmotic potential of the sap, which was not measured. This osmotic potential is near zero, typically $>-0.1 \mathrm{MPa}$, and remains essentially constant with leaf water potentials decreasing to $-1.5 \mathrm{MPa}$ in many species (Boyer, 1967; Boyer, 1969; Day et al., 1981). The osmotic potential of the leaf tissue $(\pi)$ was measured with a freezing point depression osmometer (Knauer) or with a dew-point osmometer (Wescor), after thawing of the frozen leaves and a centrifugation procedure to collect and purify the cell sap. Relative water content $(R W C)$ of the leaves was measured according to the method of Stocker (1929), which includes determination of: (1) fresh weight direct after excision $\left(w_{f}\right),(2)$ turgid weight after an overnight saturation in small polythene cups $\left(w_{t}\right)$ and $(3)$ weight after oven drying $\left(w_{\mathrm{d}}\right)$, with the equation:

$$
R W C=\frac{w_{\mathrm{f}}-w_{\mathrm{d}}}{w_{\mathrm{t}}-w_{\mathrm{d}}}
$$

Turgor $(P)$ was calculated with the equation: $P=\psi-\pi$. The bulk modulus of elasticity $(B M E)$ was calculated with the equation:

$$
B M E=\frac{\Delta P}{\Delta R W C}
$$

Some preliminary measurements showed that the water status of two succeeding leaves was almost the same. Therefore, we assumed that $\psi, \pi, P$ and $R W C$, measured at two subsequent top leaves (or oldest green leaves) were applicable to one and the same top (or oldest green) leaf.

Stomatal conductance was measured on the lower leaf surface with a Li-cor porometer, and radiation, air humidity and cuvette temperature were recorded. Expansive growth in the field was measured every day, as the increment of the distance between two painted marks of the youngest expanding internode. Expansive growth in the controlled environment experiments was measured with an auxanometer described by Kleinendorst \& Brouwer (1970). The auxanometer was clamped on the top of the youngest expanding leaf, in such a way that the total expansive growth of the young stem parts and the youngest leaf were recorded. 


\section{Results}

Development of water shortage during the season

The growing season of 1982 was relatively dry and warm. Clear differences in soil water content between the treatments $d-d$ and $i-i$ were found from 28 May onwards (Grashoff, 1990a). On 9 June, $\psi$ at mid-day was $-1.12 \mathrm{MPa}$ in d-d and $-0.74 \mathrm{MPa}$

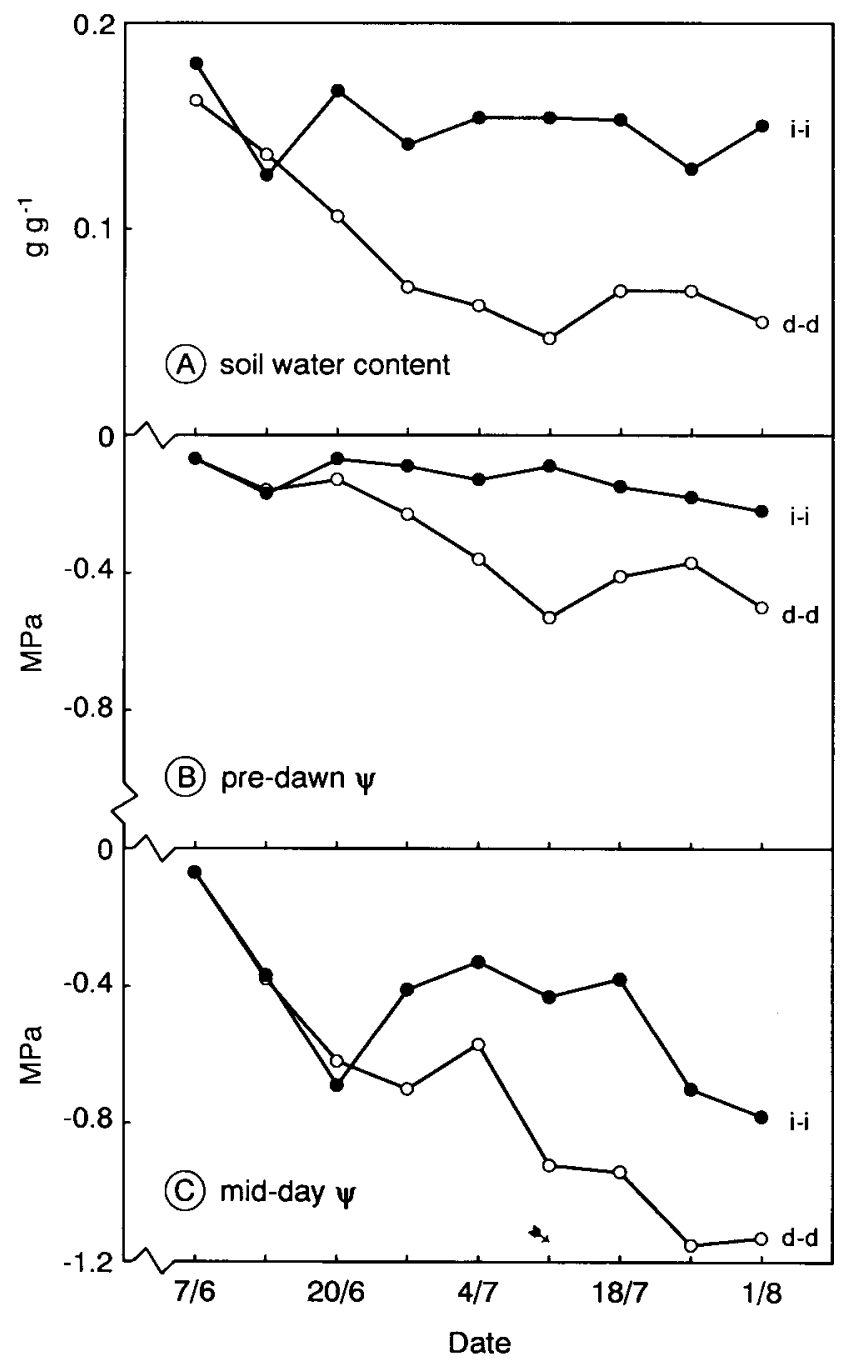

Fig. 1. Seasonal course of (A) soil water content, (B) pre-dawn $\psi$ and (C) mid-day $\psi$ in two water supply treatments in 1984. A heavy thunderstorm on 11 July (11/7) is indicated by $\searrow$. Calendar data presented as day/month. 


\section{GRASHOFF AND D. R. VERKERKE}

in $\mathrm{i}-\mathrm{i}$, at soil water contents of respectively $0.06 \mathrm{~g} \mathrm{~g}^{-1}$ (in $\mathrm{d}-\mathrm{d}$ ) and $0.11 \mathrm{~g} \mathrm{~g}^{-1}$ (in $\mathrm{i}-\mathrm{i}$ ). Differences in $\psi$ between d-d and i-i were present at almost all the following measuring days; on the last measuring day, 8 July, the mid-day $\psi$ was $-1.63 \mathrm{MPa}$ (in dd) and $-1.09 \mathrm{MPa}$ (in i-i) at soil water contents of $0.04 \mathrm{~g} \mathrm{~g}^{-1}(\mathrm{~d}-\mathrm{d})$ and $0.10 \mathrm{~g} \mathrm{~g}^{-1}(\mathrm{i}-\mathrm{i})$.

In 1984, differences in soil water content between the treatments occurred after 13 June (Figure 1a). After the soil water content in d-d fell below $0.10 \mathrm{~g} \mathrm{~g}^{-1}$ (on 20 June), pre-dawn $\psi$ followed the further decline of soil water content in d-d (Figure $1 b$ ). From that point onwards, pre-dawn and mid-day $\psi$ values (Figure 1c) were lower in d-d than in i-i. Apparently, a soil water content of $0.10 \mathrm{~g} \mathrm{~g}^{-1}$, corresponding to a pF $3(0.1 \mathrm{MPa})$ in this sandy soil type, was a critical value for the development of water shortage in the plants.

\section{Water relation characteristics}

Figure 2 shows the relation between $\psi, \pi, P$ versus $R W C$, plotted for the upper leaves of cv. Minica. This Figure represents a graphical view of the regressions needed for the analysis of plant water relations (a general analysis will be presented in the next paragraph). The linear regression analyses on $\mathrm{d}-\mathrm{d}$ and $\mathrm{i}$-i data together in

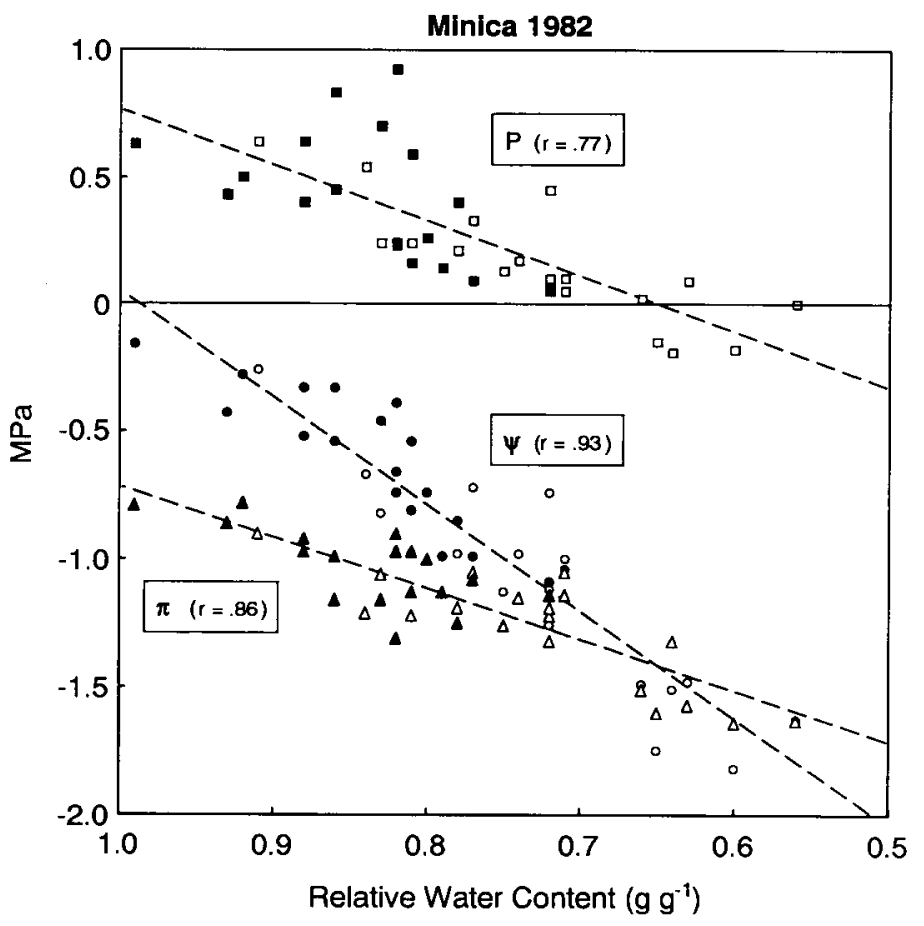

Fig. 2. Diagram of water relation characteristics for upper leaves of cv. Minica. Data obtained from 9 June to 8 July, 1982, on 7 days. Open symbols: data from d-d; closed symbols: data from i-i. 
Figure 2 show high correlation coefficients, already indicating the absence of strong effects of water supply treatment on the water relation characteristics. A majority of data points of $d-d$ were found at the right-hand side of the diagram, while $i-i$ points were located more at the left hand side. This difference in location illustrates the general difference in level of water availability between the two treatments. This is demonstrated in detail in Figure 3, where $P$ is plotted directly versus $\psi$. On 1 July $1982, P$ in the top leaves of $d-d$ was $0.5 \mathrm{MPa}$ lower than in $\mathrm{i}-\mathrm{i}$, averaged over the day. This Figure also shows, that even the smallest decline in $\psi$ results in a proportional decline in $P$.

Table 2 shows the regression analyses of the water relation characteristics for all data obtained in 1982. Linear regressions of $\psi$, respectively $\pi$ and $P$ versus $R W C$ accounted for $80 \%$, respectively $60 \%$ and $45 \%$ of the variation. Significant main effects of cultivar and of cultivar $\times R W C$ interactions were not found. A significant

Table 2. Results of regression analysis of water potential $(\psi)$, osmotic potential $(\pi)$ and turgor $(P)$ versus relative water content $(R C W)$ : percentage of accounted variation, coefficients a and b. Fitted lines have the following form: $y=\mathrm{a} \times R W C+\mathrm{b}$, where $y$ is $\psi, \pi$ or $P$; cv $=$ cultivar; water $=$ water supply treatment; leaf = leaf position; $\mathrm{cv}$, water, leaf and interaction effects were subsequently included in the analysis. $^{* * *}=$ significant effect $($ at $P<0.01)$; n.s. $=$ not significant. Data obtained from measurements on 7 data between 9 June and 8 July, 1982, on experimental farm Droevendaal.

\begin{tabular}{|c|c|c|c|c|c|c|c|}
\hline \multirow[t]{2}{*}{$y$} & \multicolumn{7}{|c|}{$\%$ of accounted variation (and coefficients $a$ and $b$ ) } \\
\hline & $R W C$ & $\begin{array}{l}(R W C+ \\
\mathrm{cv})\end{array}$ & $\begin{array}{l}(R W C+ \\
\text { cv })+ \\
(R W C \times \\
\text { cv) } \\
\text { interaction }\end{array}$ & $\begin{array}{l}\text { (RWC+ } \\
\text { water) }\end{array}$ & $\begin{array}{l}(R W C+ \\
\text { water })+ \\
(R W C \times \\
\text { water }) \\
\text { interaction }\end{array}$ & $\begin{array}{l}\text { (RWC+ } \\
\text { leaf) }\end{array}$ & $\begin{array}{l}(R W C+ \\
\text { leaf })+ \\
(R W C \times \\
\text { leaf }) \\
\text { interaction }\end{array}$ \\
\hline$\psi$ & $\begin{array}{l}81.1^{* * *} \\
(\mathrm{a}=3.78) \\
(\mathrm{b}=-3.84)\end{array}$ & 81.0 n.s. & 80.8 n.s. & $\begin{array}{l}85.3^{* * *} \\
(\mathrm{a}=3.19) \\
(\mathrm{b} 1=-3.47 \\
\mathrm{d}-\mathrm{d}) \\
(\mathrm{b} 2=-3.25 \\
\mathrm{i}-\mathrm{i})\end{array}$ & 85.5 n.s. & 81.1 n.s. & 81.0 n.s. \\
\hline$\pi$ & $\begin{array}{l}60.5^{* * *} \\
(\mathrm{a}=2.10) \\
(\mathrm{b}=-2.72)\end{array}$ & 60.1 n.s. & 59.7 n.s. & $\begin{array}{l}61.9^{* * *} \\
(\mathrm{a}=1.87) \\
(\mathrm{b} 1=-2.57 \\
\text { d-d) } \\
(\mathrm{b} 2=-2.48 \\
\mathrm{i}-\mathrm{i})\end{array}$ & 61.9 n.s. & $\begin{array}{l}77.6^{* * *} \\
(\mathrm{a}=1.87) \\
\text { (b1=-2.41; } \\
\text { lower leaf) } \\
\text { (b2=-2.64; } \\
\text { upper leaf) }\end{array}$ & $77.6 \mathrm{n} . \mathrm{s}$. \\
\hline$P$ & $\begin{array}{l}43.5^{* * *} \\
(a=1.68) \\
(b=-1.13)\end{array}$ & 42.7 n.s. & 42.4 n.s. & $\begin{array}{l}47.5^{* * *} \\
(\mathrm{a}=1.32) \\
(\mathrm{b} 1=-0.90 ; \\
\mathrm{d}-\mathrm{d}) \\
(\mathrm{b} 2=-0.77 \\
\mathrm{i}-\mathrm{i})\end{array}$ & 47.3 n.s. & $\begin{array}{l}65.9^{* * *} \\
(\mathrm{a}=1.93) \\
(\mathrm{b}=-1.46 ; \\
\text { lower leaf) } \\
\text { (b2=-1.21; } \\
\text { upper leaf) }\end{array}$ & 65.9 n.s. \\
\hline
\end{tabular}




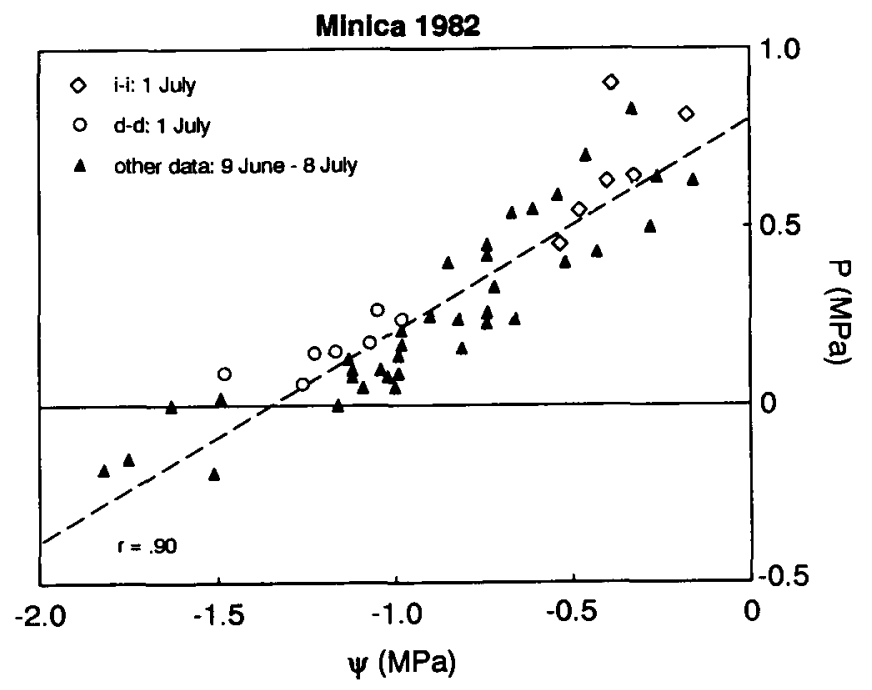

Fig. 3. Turgor $(P)$ versus water potential $(\psi)$ for upper leaves of cv. Minica. Open circles: data from d-d at $1 \mathrm{July}$; open diamonds: data from i-i at 1 July. Closed triangles: all other data obtained between 9 June and $8 \mathrm{July}, 1982$.

main effect of water supply treatment was found, but this increased the percentage of accounted variation with only 1.5 to $4 \%$ and the differences in intercepts were very small. For instance, the intercept of the regression of $\pi$ versus $R W C+$ water was $-2.48 \mathrm{MPa}$ in $\mathrm{i}-\mathrm{i}$ and only $0.09 \mathrm{MPa}$ lower in d-d (Table 2). This shows that osmotic adjustment due to water supply treatment was negligible. Significant $R W C \times$ water supply treatment interactions were absent, which implies that the slopes of the regression lines were the same for both treatments. It is concluded that the bulk modulus of elasticity $(B M E)$, defined as the slope of the regression of $P$ versus $R W C$, showed no adaptation due to water supply treatment. Only a clear main effect of leaf position was present. When upper leaves and lower leaves were separated in the analysis, the percentage of variation accounted for increased with $15 \%$ and $20 \%$ for $\pi$, respectively $P$ versus $R W C$ (Table 2). From the data in this Table it was calculated that $\pi$ at full turgidity was $-0.54 \mathrm{MPa}$ for the lower leaves and -0.77 MPa for the upper leaves which implies that the lower leaves contained $30 \%$ less osmotically active solutes. As no differences in $B M E$ were found, lower leaves lost their turgor at an $R W C$ of 0.75 , but upper leaves not until 0.65 . Important cultivar $x$ treatment interactions were not found in any of the relations showed before.

Table 3 shows the regression analysis for $P$ versus $\psi$ of 1982 and 1984, combined for all cultivars. The regression accounted for $60 \%$ of the variation in both years. Significant effects of cultivar, water supply treatment and interactions were not found and differences between the years were small. $P$-value at $\psi=0$ (which means full turgidity), was $0.8 \mathrm{MPa}$ in 1982 and $0.9 \mathrm{MPa}$ in 1984 and the $\psi$-value at zero $P$ was $-1.5 \mathrm{MPa}$ in both years. These data show that osmotic adjustment and adapta- 
Table 3. Results of regression analysis of turgor $(P)$ versus water potential $(\psi)$ : percentage of accounted variation, coefficients a and $b$. Fitted lines have the following form: $P=a \times \psi+b$; cv $=$ cultivar; water $=$ water supply treatment; leaf = leaf position; $\mathrm{cv}$, water, leaf and interaction effects were subsequently included in the analysis. ${ }^{* *}=$ significant effect $($ at $P<0.01) ;$ n.s. $=$ not significant. Data obtained from measurements in 1982 and in 1984 on experimental farm Droevendaal.

\begin{tabular}{|c|c|c|c|c|c|c|c|}
\hline \multirow{2}{*}{$\begin{array}{l}P \text { fitted } \\
\text { for year }\end{array}$} & \multicolumn{7}{|c|}{$\%$ of accounted variation (and coefficients $a$ and $b$ ) } \\
\hline & $\psi$ & $(\psi+\mathrm{cv})$ & $\begin{array}{l}(\psi+\mathrm{cv}) \\
+(\psi \times \\
\mathrm{cv}) \\
\text { interaction }\end{array}$ & $(\psi+$ water $)$ & $\begin{array}{l}(\psi+\text { water }) \\
+(\psi \times \\
\text { water }) \\
\text { interaction }\end{array}$ & $(\psi+$ leaf $)$ & $\begin{array}{l}(\psi+\text { leaf }) \\
+(\psi \times \\
\text { leaf }) \\
\text { interaction }\end{array}$ \\
\hline 1982 & $\begin{array}{l}61.8^{* * *} \\
(a=0.48) \\
(b=0.61)\end{array}$ & 61.3 n.s. & $60.8 \mathrm{n} . \mathrm{s}$ & $61.6 \mathrm{~ns} . \mathrm{s}$ & $61.5 \mathrm{n} . \mathrm{s}$. & $\begin{array}{l}83.4^{* * *} \\
(\mathrm{a}=0.52) \\
(\mathrm{b} 1=0.52 \\
\text { lower leaf) } \\
\mathrm{b} 2=0.76 \\
\text { upper leaf) }\end{array}$ & 83.8 n.s. \\
\hline 1984 & $\begin{array}{l}59.4^{* * *} \\
(\mathrm{a}=0.61) \\
(\mathrm{b}=0.91)\end{array}$ & 59.2 n.s. & 58.8 n.s. & 59.0 n.s. & 58.9 n.s. & $\begin{array}{l}\text { (lower leaves } \\
\text { not measured) }\end{array}$ & \\
\hline
\end{tabular}

tion of $B M E$ due to cultivar, water supply treatment or season were absent or negligible. Again, only a significant effect of leaf position was present. After split-up of the regression analysis in lower and upper leaves (1982-data) the variation accounted for increased up to $80 \%(P<0.001)$. In the lower leaves, complete wilting $(P=0)$ was reached already at a $\psi$ of $-1.0 \mathrm{MPa}$ but in upper leaves this happened not before a $\psi$ of $-1.5 \mathrm{MPa}$.

\section{Water shortage and expansive growth}

During and shortly after flowering, the average rate of internode expansive growth in the field in i-i was, dependent on the cultivar, 2.5 to 5 times higher than in d-d treatments (Table 4). In the controlled environment, the rate of expansive growth (of the young stem parts and the youngest leaf together) followed the changes in $P$. At the start of the light period transpiration increased, and resulted in a sharp decline in $\psi$ and $P$ of the top leaves and a concomitant cessation of expansive growth. During the light period the expansive growth slightly recovered but remained very low. After the end of the light period, $\psi$ and $P$ raised importantly, and the expansive growth immediately recovered. The relation between $P$ and the rate of expansive growth is plotted in Figure 4. Although there is some scatter, the data indicate that expansive growth is linearly related to $P$. Linear regression (which accounted for $70 \%$ of the variation) showed the absence of a minimum turgor for expansive growth (turgor threshold). 


\section{GRASHOFF AND D. R. VERKERKE}

Table 4. Internode expansive growth rate $\left(\mathrm{mm} \mathrm{d}^{-1}\right)$ of four faba bean cultivars at two water supply treatments (d-d and i-i), averaged over four periods of measurements in the field in 1982 (Experimental farm Droevendaal).

\begin{tabular}{llc}
\hline Cultivar & \multicolumn{2}{l}{ Internode expansive growth rate $\left(\mathrm{mm} \mathrm{d}^{-1}\right)$} \\
\cline { 2 - 3 } & $\mathrm{d}-\mathrm{d}$ & $\mathrm{i}-\mathrm{i}$ \\
Minica & 1.0 & 3.0 \\
Felix & 0.5 & 2.0 \\
Kristall & 2.0 & 5.0 \\
Wierboon & 1.5 & 5.0 \\
\hline
\end{tabular}

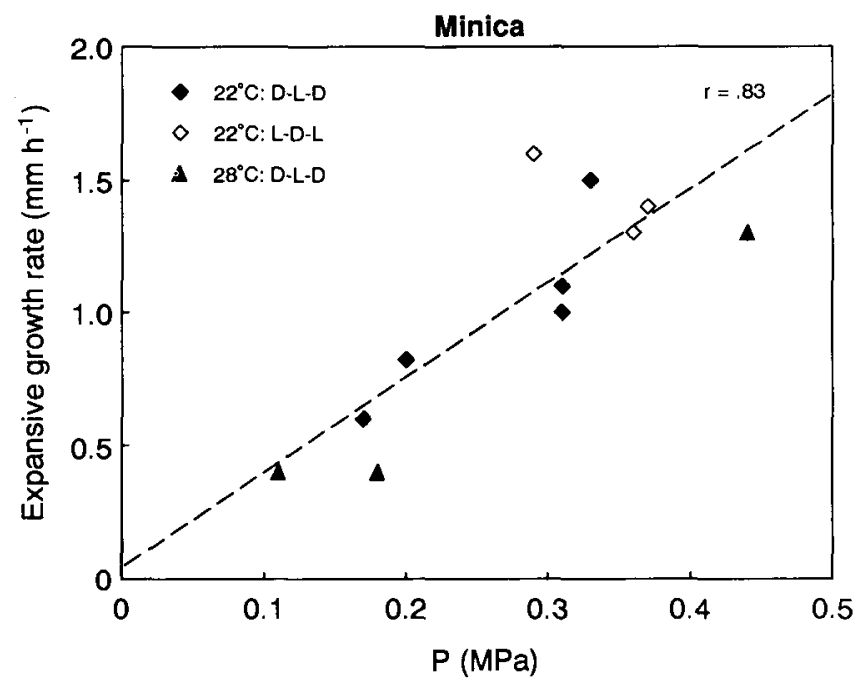

Fig. 4. Expansive growth versus turgor $(P)$ for $\mathrm{cv}$. Minica. All data from experiments under controlled conditions, 1983.

\section{Stomatal conductance}

In Figure 5a the water potential $(\psi)$ of top leaves was plotted against the stomatal conductance. Data pairs of $\psi$-conductance measurements were collected diurnally under strongly varying environmental conditions, which resulted in a large scatter pattern. According to Jarvis (1976), a curvilinear border line can be estimated, indicating the maximum stomatal conductance at a given $\psi$-value. This border line decreased with $\psi$ from a level at about $1.0 \mathrm{~cm} \mathrm{~s}^{-1}$ at full turgidity, following a negative exponential curve to zero at a $\psi$ of about $-1.6 \mathrm{MPa}$. Clear differences between cultivars were not found. 

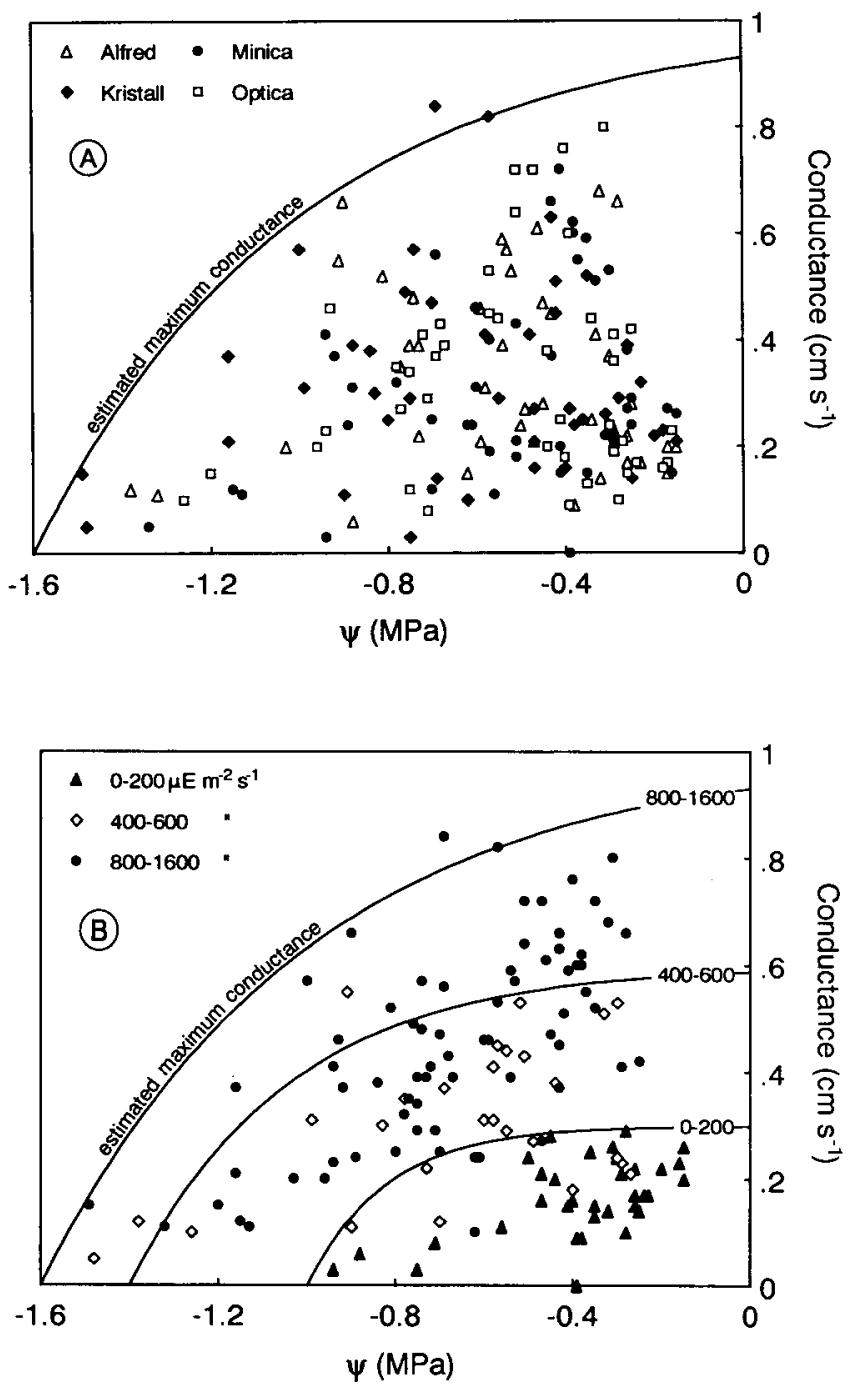

Fig. 5. Stomatal conductance, as influenced by environment, for the top leaves of the four varieties tested in 1984. (A) all data versus water potential $(\psi)$ and (B) all data versus $\psi$, classified in different radiation levels. Curves are fitted using the equation: $c=c_{\max }\left(1-\exp \left(-\left(\left(\psi-\psi_{\mathrm{c} 0}\right) /\left(a \times c_{\max }\right)\right)\right)\right) ; c_{\max }=\operatorname{maxi}-$ mum stomatal conductance; $\psi_{\mathrm{c} 0}=\psi$ at stomatal conductance $=0 ; a=$ initial slope at $\psi_{\mathrm{c} 0}$.

From Figure $5 \mathrm{~b}$ it can be seen that the scatter in Figure $5 \mathrm{a}$ is strongly determined by the level of light intensity. At each light intensity, maximum stomatal conductance can be plotted versus $\psi$, following the same kind of negative exponential curve. 


\section{Discussion}

The water relation characteristics of the top leaves of faba beans (Figure 2) showed much resemblance to those found by Turner et al. (1978) in soya beans. In agreement with Turner et al. (1978) we found linear relations. However, curves are theoretically more correct (Weatherley, 1970), but the scatter in field data was too large to find significant effects of non-linear regression.

Lower leaves always contained a lower solute content (a higher $\pi$ ) than upper leaves. This may explain why lower leaves in the field wilt earlier than upper leaves during the development of water shortage. The observed differences between upper and lower leaves cannot be explained in terms of adaptation to water shortage, since differences between water supply treatments were absent (Table 2). The lower solute content of lower (oldest green) leaves might be related with a lower light exposure and attraction of osmotically active solutes by the developing pods.

The results presented in this paper do not show any adaptation of the bulk modulus of elasticity $(B M E)$ due to water supply treatment. Also in faba beans, Elston et al. (1976) found an adaptation of $B M E$ in a dry relative to an irrigated treatment. This adaptation, however, was not sufficient for compensating the general fall of $P$ during water shortage.

Similar to soya beans (Turner et al., 1978), faba bean cultivars did not show any important osmotic adjustment or adaptation of $B M E$ due to water supply or season (Tables 2 and 3; Figures 2 and 3). It implies, that each decline in leaf- $R W C$ is followed by a proportional decline in $\psi$ and in $P$. So the six faba bean cultivars which we tested, showed a general lack of mechanisms to maintain $P$-level during water shortage.

In our experiments indoors, expansive growth declined proportional with declining $P$ (Figure 4). This kind of relation is in agreement with results of Bunce (1977). Hsiao et al. (1976a) found in sorghum even a sharper decline of expansive growth with $P$, namely an exponential relation, with a turgor threshold of 0.05 to 0.1 MPa. However, Bunce (1977) showed that turgor threshold values may depend on growing conditions.

Anyhow, applying the relationship between expansive growth and $P$ (Figure 4) to the field situation, it may be expected that expansive growth falls sharply when $\psi$ and $P$ decline due to an increasing water shortage (Figure 1). This prospect was confirmed by our field data, showing a strong reduction of internode expansion rate (Table 4), plant length and leaf area index (Grashoff, 1990a) in d-d treatments, relative to $\mathrm{i}-\mathrm{i}$. Full recovery of expansive growth during the night is not likely in d-d, since even predrawn $\psi$ remains lower than in $\mathrm{i}-\mathrm{i}$, below a critical soil water content (Figure 1). Moreover, Karamanos et al. (1982) established a close correlation between $P$ at noon and final leaf size in field grown Vicia faba.

Consequently, as a decline in $\psi$ and $P$ results in a decline in all metabolic processes (Hsiao \& Acevedo, 1974), less photosynthate will be incorporated into structural material of young stem parts and young leaves. Grashoff (1990a) showed that the reduction of stem elongation rate during water shortage was immediately followed by a reduction of stem dry matter accumulation rate. Water shortage might 
result in a higher specific leaf weight (Grashof, 1990a), probably by starch accumulation. Recently, however, Bunce (1990) showed an increased export of photosynthate from young leaves under mild water shortage. Spraying of abscisic acid (ABA) mimicked this effect and Bunce (1990) concluded that ABA, perhaps even more than just turgor decline, might mediate the effects of mild water shortage, due to an inhibition of cell wall elongation. So, the reduction in expansive growth of the vegetative top by water shortage might bring about a shift in assimilate distribution in favour of other sink organs.

This reasoning, however, only holds true when the assimilate source, photosynthesis, is not or less reduced. Our evidence on photosynthesis is derived from data on maximal stomatal conductance (Figure 5). The estimated borderlines suggest that maximum stomatal conductance is negative exponentially related to $\psi$ over a wide range. As in general leaf mesophyll conductance and $\psi$ decline concomitantly (Hsiao, 1973), it seems that in faba beans a negative exponential relation exists between rate of photosynthesis and $\psi$ (Figure 5). This agrees with the results of Kassam (1973). He provided evidence for the faba bean cultivar Maris Bead, that stomatal conductance was hardly reduced at small declines of $\psi$ and $P$, until a threshold value at low $\psi$, where the leaves were almost flaccid. Boyer (1970) and Hsiao et al. (1976b) also found this kind of non-linear relations for other crops. Turner et al. (1978) showed with soya beans, that a decrease of photosynthesis commenced at a $\psi$ below 1.5 to $1.7 \mathrm{MPa}$. Grashoff (1990a) showed in field experiments in 1980 and 1981 , that stem elongation was already markedly reduced in the d-i treatment, while total dry matter accumulation rate was still the same in $\mathrm{i}-\mathrm{i}$ and $\mathrm{d}-\mathrm{i}$.

According to Shimshi (1963) and Slatyer \& Bierhuizen (1964), a decrease of stomatal conductance reduces transpiration rate more than rate of photosynthesis. Vos \& Groenwold (1989) reported increasing water use efficiency at water shortage in potatoes. Passioura (1977) found important cultivar differences in water use efficiency in wheat. Verkerke (pers. comm.) found increased water use efficiency in faba beans when water shortage was created in water cultures with polyethylene glycol. This shows that photosynthesis might be even less sensitive to increasing water shortage than could be derived from the response of stomatal conductance.

The combination of the relations of photosynthesis and expansive growth with $P$ or $\psi$ (Figure 6) clearly indicate the development during water shortage of an assimilate surplus. Since also no osmotic adjustment was observed, these assimilates become available for investment elsewhere in the plant. According to the theory of the functional equilibrium (Brouwer, 1983), the roots might benefit from these assimilates. However, when mild water shortage occurs in reproductive plants during flowering, young developing pods on the stem basis might compete successfully for assimilates. Actually, Grashoff (1990b) established an increased retention of the first pods under mild water shortage during flowering, thus providing the basis for an early and strong reproductive sink and a high final seed yield. It has to be emphasized that mild water shortage should be released after cessation of vegetative growth. The strongest positive effects on dry matter partition and seed yield were found in treatments with mild water shortage during flowering and plenty of water afterwards (Grashoff, 1990a). It seems remarkable that young pods were able to 


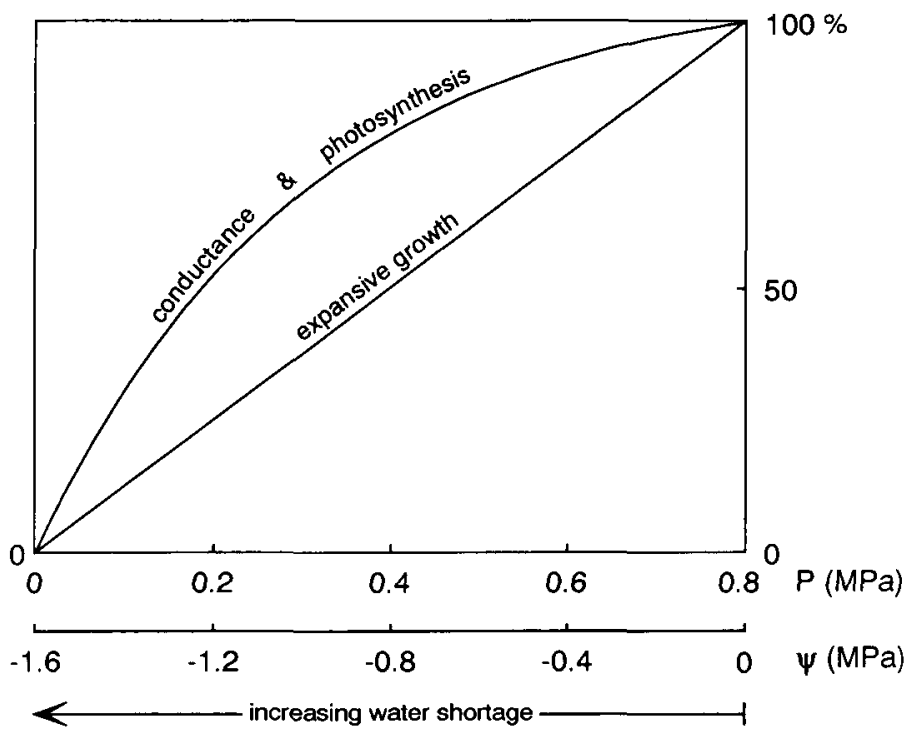

Fig. 6. Hypothetical relations between rate of expansive growth, conductance and photosynthesis versus water potential $(\psi)$ and turgor $(P)$, for faba beans according to the results of this paper and for various crop types, according to Hsiao et al. (1976b) and others (see text); NB: shapes of curves are a qualitative representation!

grow better under conditions with mild water shortage than the vegetative top. Additional research on the nature of this mechanism is interesting, as it might be a key factor in the distribution of assimilates in the plant.

The results presented in this paper provide no evidence for important cultivar differences in water relation characteristics. This agrees with the results of Vos \& Groenwold (1988) for potato cultivars. Since some cultivars did differ significantly in the response on pattern of water supply (Grashoff, 1990a), it is questionable whether measurement of the water relation characteristics is an effective way to identify genotypic tolerance or resistance to water shortage.

Varietal differences in properties that enable the plant to avoid water shortage (e.g. rooting depth) or to escape from it (e.g. timing of flowering period, rate of development) and differences in water use efficiency may be more relevant characteristics. However, the improvement of tolerance or resistance to water shortage may not be considered apart from dry matter partitioning characteristics.

\section{Acknowledgements}

The authors wish to expres their thanks to Dr J. Goudriaan (LUW) for his generous help with the interpretation of the stomatal conductance data. 


\section{References}

Boyer, J. S., 1967. Leaf water potentials measured with a pressure chamber. Plant Physiology 42: 133137.

Boyer, J. S., 1969. Measurement of the water status of plants. Annual Reviews of Plant Physiology 20: 351-364.

Boyer, J. S., 1970. Leaf enlargement and metabolic rates in corn, soybean, and sunflower at various leaf water potentials. Plant Physiology 46: 233-235.

Brouwer, R., 1983. Functional equilibrium: sense or nonsense? Netherlands Journal of Agricultural Science 31: 335-348.

Bunce, J. A., 1977. Leaf elongation in relation to leaf water potential in soybean. Journal of Experimental Botany 28: 156-161.

Bunce, J. A., 1990. Abscisic acid mimics effects of dehydration on area expansion and photosynthetic partitioning in young soybean leaves. Plant, Cell and Environment 13: 295-298.

Day, W., D. W. Lawlor \& B. J. Legg, 1981. The effects of drought on barley: soil and plant water relations. Journal of Agricultural Science (Cambridge) 96: 61-77.

Elston, J., A. J. Karamanos, A. H. Kassam \& R. M. Wadsworth, 1976. The water relations of the field bean crop. Philosophical Transactions of the Royal Society of London B 273: 581-591.

Grashoff, 1990a. Effect of pattern of water supply on Vicia faba L. 1. Dry matter partitioning and yield variability. Netherlands Journal of Agricultural Science 38: 21-44.

Grashoff, 1990b. Effect of pattern of water supply on Vicia faba L. 2. Pod retention and filling, and dry matter partitioning, production and water use. Netherlands Journal of Agricultural Science 38: 131143.

Hellkvist, J., G. P. Richards \& P. G. Jarvis, 1974. Vertical gradients of water potential and tissue water relations in sitka spruce trees measured with the pressure chamber. Journal of Applied Ecology 11: 637-667.

Hsiao, T. C., 1973. Plant responses to water stress. Annual Reviews of Plant Physiology 24: 519-570.

Hsiao, T. C. \& E. Acevedo, 1974. Plant responses to water deficits, water use efficiency, and drought resistance. Agricultural Meteorology 14: 59-84.

Hsiao, T. C., E. Acevedo, E. Fereres \& D. W. Henderson, 1976a. Water stress, growth, and osmotic adjustment. Philosophical Transactions of the Royal Society of London B 273: 479-500.

Hsiao, T. C., E. Fereres, E. Acevedo \& D. W. Henderson, 1976b. Water stress and dynamics of growth and yield of crop plants. In: O. L. Lange, L. Kappen \& E. D. Schulze (Eds), Water and Plant Life, p. 281-305. Springer Verlag, Berlin.

Jarvis, P. G., 1976. The interpretation of the variations in leaf water potential and stomatal conductance found in canopies in the field. Philosophical Transactions of the Royal Society of London B 273: 593 610.

Jones, M. M. \& N. C. Turner, 1978. Osmotic adjustment in leaves of sorghum in response to water deficits. Plant Physiology 61: 122-126.

Karamanos, A. J., J. Elston \& R. M. Wadsworth, 1982. Water stress and leaf growth of field beans ( $\mathrm{Vi}$ cia faba L.) in the field: water potentials and laminar expansion. Annals of Botany 49: 815-826.

Kassam, A. H., 1973. The influence of light and water deficit upon diffusive resistance of leaves of Vicia faba L. New Phytologist 72: 557-570.

Kassam, A. H. \& J. Elston, 1974. Seasonal changes in the status of water and tissue characteristics of leaves of Vicia faba L. Annals of Botany 38: 419-429.

Kleinendorst, A. \& R. Brouwer, 1970. The effect of temperature of the root medium and of the growing point of the shoot on growth, water content and sugar content of maize leaves. Netherlands Journal of Agricultural Science 18: 140-148.

Nonami, H. \& J. S. Boyer, 1988. Turgor and growth at low water potentials. Plant Physiology 90: 789804.

Passioura, J. B., 1977. Grain yield, harvest index and water use of wheat. The Journal of the Australian Institute of Agricultural Science September/December, 1977: 117-120.

Scholander, P. F., H. T. Hammel, E. D. Bradstreet \& E. A. Hemmingsen, 1965. Sap pressure in vascular plants. Science 148: 330-346.

Shimshi, D., 1963. Effect of soil moisture and phenylmercuric acetate upon stomatal aperture, transpi- 


\section{GRASHOFF AND D. R. VERKERKE}

ration, and photosynthesis. Plant Physiology 38: 713-721.

Slatyer, R. O. \& J. F. Bierhuizen, 1964. The influence of several transpiration suppressants on transpiration, photosynthesis, and water use efficiency of cotton leaves. Australian Journal of Biological Science 7: 131-146.

Sobrado, M. A. \& N. C. Turner, 1983. Influence of water deficits on the water relations characteristics and productivity of wild and cultivated sunflowers. Australian Journal of Plant Physiology 10: 195203.

Stocker, O., 1929. Wasserdefizit von Gefasspflanzen in verschiedenen Klimazonen. Planta 7: 382-387.

Turner, N. C., J. E. Begg, H. M. Rawson, S. D. English \& A. B. Harn, 1978. Agronomic and physiological responses of soybean and sorghum crops to water deficits. III. Components of leaf water potential, leaf conductance, ${ }^{14} \mathrm{CO}_{2}$ photosynthesis, and adaptation to water deficits. Australian Journal of Plant Physiology 5: 179-194.

Volkenburgh, E. van \& J. S. Boyer, 1985. Inhibitory effects of water deficit on maize leaf elongation. Plant Physiology 77: 190-194.

Vos, J. \& J. Groenwold, 1988. Water relations of potato leaves. I. Diurnal changes, gradients in the canopy, and effects of leaf-insertion number, cultivar and drought. Annals of Botany 62: 363-371.

Vos, J. \& J. Groenwold, 1989. Characteristics of photosynthesis and conductance of potato canopies and the effect of cultivar and transient drought. Field Crops Research 20: 237-250.

Weatherley, P., 1970. Some aspects of water relations. Advances in Botanical Research 3: 171-206. 